\title{
Effects of early spasticity treatment on children with hemiplegic cerebral palsy: a preliminary study
}

\author{
Efeitos do tratamento precoce da espasticidade em crianças com \\ paralisia cerebral hemiplégica: um estudo preliminar \\ Marise Bueno Zonta1', Isac Bruck², Marilene Puppi', Sandra Muzzolon', \\ Arnolfo de Carvalho Neto ${ }^{5}$, Lúcia Helena Coutinho dos Santos ${ }^{6}$
}

\begin{abstract}
Objective: To compare motor and functional performance of two groups of children with hemiplegic cerebral palsy (HCP). Only the study group (SG) received early treatment of spasticity with botulinum neurotoxin type A (BXT-A). Methods: Gross Motor Function Measure (GMFM), functional performance (Pediatric Evaluation of Disability Inventory - PEDI), range of movement, gait pattern (Physician Rating Scale - PRS) and the speed of hand movements were considered. Results: The SG, composed of 11 HCP (45.64 6 .3 months), was assessed in relation to the comparison group, composed of $13 \mathrm{HCP}$ (45.92 16.4 months). SG showed higher scores in four of the five GMFM dimensions, which included scores that were statistically significant for dimension B, and higher scores in five of the six areas evaluated in the PEDI. Active wrist extension, the speed of hand movements and PRS score were higher in the SG. Conclusion: Children who received early BXT-A treatment for spasticity showed higher scores in motor and functional performance.
\end{abstract}

Key words: child, botulinum toxins, type A, cerebral palsy, hemiplegia.

RESUMO

Objetivo: Comparar a performance motora e funcional de dois grupos de crianças com paralisia cerebral hemiplégica (PCH). Apenas o grupo de estudo (GE) recebeu tratamento precoce da espasticidade com toxina botulínica do tipo A (BXT-A). Métodos: Foram considerados a Função Motora Grossa (Gross Motor Function Measure - GMFM), performance funcional (Pediatric Evaluation of Disability Inventory - PEDI), amplitude de movimento, padrão da marcha (Physician Rating Scale - PRS) e a velocidade de movimento das mãos. Resultados: 0 GE, composto

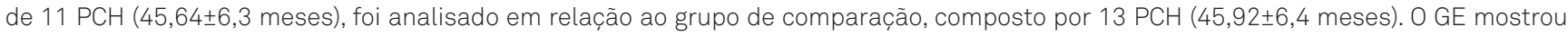
maiores escores em quatro das cinco dimensões da GMFM, sendo a diferença estatisticamente significativa na dimensão B, e melhores escores em cinco das seis áreas avaliadas na PEDI. A extensão ativa do punho, a velocidade de movimento das mãos e o escore na PRS foram maiores no GE. Conclusão: As crianças que receberam tratamento precoce da espasticidade com BXT-A mostraram melhores escores motores e funcionais.

Palavras-Chave: criança, toxinas botulínicas tipo A, paralisia cerebral, hemiplegia.

The ultimate goal for the treatment of children with cerebral palsy (CP) is an improvement in functionality and increased independence, which will prepare these children for adult life ${ }^{1}$. The prognosis of a child with CP often depends on the type and severity of the palsy and the accompanying medical comorbidities $^{2}$. In hemiplegic cerebral palsy (HCP), different severities and combinations of impairments in sensory function, perception, muscle tone, muscle strength and range of motion contribute to their motor dysfunction. Furthermore, these factors should be evaluated and managed because functionality is a component of overall health, and the appropriate combinations of interventions can improve function ${ }^{3}$.

${ }^{1} M D$, PhD; Physical therapist, Neuropediatrics Center, Clinics Hospital, Universidade Federal do Paraná (UFPR), Curitiba PR, Brazil;

${ }^{2} \mathrm{MD}$; Child Neurology Professor, Pediatric Department, UFPR, Curitiba PR, Brazil;

${ }^{3}$ Occupational Therapist, Neuropediatrics Center, UFPR, Curitiba PR, Brazil;

${ }^{4}$ Psy, MSc; Psychologist, Neuropediatrics Center, Clinics Hospital, UFPR, Curitiba PR, Brazil;

${ }^{5} \mathrm{MD}$, PhD; Neuroradiologist, Professor, Internal Medicine Department, UFPR, Curitiba PR, Brazil;

${ }^{6} \mathrm{MD}$; Pediatric Neurologist, Adjunct Professor, Pediatric Department, UFPR, Curitiba PR, Brazil.

Correspondence: Marise Bueno Zonta; Rua Floriano Essenfelder 81; 80060-270 Curitiba PR - Brasil; E-mail: marisebzonta@gmail.com

Conflict of interest: There is no conflict of interest to declare.

Received 03 July 2012; Received in final form 25 February 2013; Accepted 04 March 2013. 
Spasticity is a prevalent, disabling clinical symptom for children with $\mathrm{HCP}^{4}$ and develops over time ${ }^{1}$ concomitantly with motor development. This symptom influences motor learning and the acquisition of functional skills. Several studies have reported the effectiveness of botulinum neurotoxin type A (BXT-A) in reducing muscle tone and improving function in children with $\mathrm{CP}^{4-6}$. This treatment has been thought to facilitate the learning of more normal movement patterns ${ }^{7}$. No studies have focused on the influence of BXT-A on motor learning during the first months of life, which is a critical period for neurological development, or on the effects of this agent on the gradual consolidation of abnormal patterns of movement. However, previous observations describing improved responses in young children without the development of deformities and more structured learning potential ${ }^{6,8}$ suggest that there is a critical time during growth and development when the management of upper and lower limb spasticity in children with HCP is likely to be optimal.

The objectives of the current study were to describe the functional trajectory of infants subjected to early treatment of spasticity - study group (SG) - and compare their motor and functional performance to a comparison group (CG), composed by children who were not treated with BXT-A.

\section{METHODS}

The SG was part of a cohort follow-up from a program that evaluated babies who were at risk at the Hospital de Clínicas of the Federal University of Paraná (UFPR), a tertiary centre for high risk gestations. Infants with the diagnosis of HCP who were treated with BXT-A before two years of age were included in this study. All of the included subjects were at levels I and II, according to the Gross Motor Function Classification System (GMFCS) ${ }^{9}$. After approval by the Human Research Ethics Committee of the Hospital de Clínicas of the UFPR, 13 children were consecutively enrolled into this study from November 2001 to November 2003. Two infants were excluded because of a lack of follow-up.

At the end of three years of monitoring, the SG motor and functional performance was assessed and compared to another group in a cross-sectional study. The CG was composed of children with HCP at levels I and II, according to GMFCS 9 . These patients were referred from other clinical services after three years of age and were not exposed to BXT-A or orthopaedic surgery. One HCP child was excluded because he was at level III, according to GMFCS 9 . Informed consent was obtained from the parents/guardians of all participants.

\section{Intervention}

The BXT-A injections were administered under general anaesthesia using electro-stimulation guidance (model NS
252J, Fisher \& Paykel Electronics, Auckland, New Zealand). Injections were administered to at least two sites per muscle belly with a maximum dose of $50 \mathrm{U} /$ site. Passive and active evaluations of spasticity, passive range of motion in the target joint, muscle strength and gait and hand function observations were performed to determine if the subjects' spasticity caused discomfort, interfered with their ability to function or their acquisition of developmental milestones, or it will lead to musculoskeletal deformity. After this, the author LHCS determined treatment goals and discussed it with caregiver/child. If the family planed vacations or any other impediment for the treatment, the session was postponed ${ }^{10}$. Treatment was individualised with no standardisation of the muscle group, dose, number of sessions or age at the initiation of treatment. The toxin used was BXT-A (BOTOX ${ }^{\circledR}$, Allergan, Irvine, CA, USA) at a dilution of $100 \mathrm{U}$ in $1 \mathrm{~mL}$ of $0.9 \% \mathrm{NaCl}$ solution. At each assessment with the multidisciplinary team, along with the assessment of the need for intervention with the toxin - and independently of the need for it at that time -, caregivers were instructed on how to train motor skills corresponding to each stage of development. The multidisciplinary team has remained the same throughout follow-up. The patients were revaluated one and three months after application. The next medical reassessments were defined on a case-by-case basis.

\section{Outcomes measures used in monitoring of the study group}

The considered data were: initial age and time of attendance, number of medical evaluations, number of blockades with BXT-A, interval between sessions and medical re-evaluation, selected and applied muscles in each session, BXT-A dose per kg and number of sessions. Evaluation of spasticity ${ }^{11}$, range of active and passive extension of the wrist evaluated with a goniometer drive, and gait pattern (Physician's Rating Scale - PRS) ${ }^{12}$ were performed during each clinical evaluation always by LHCS. A periodic Gross Motor Function Measure (GMFM)-88 ${ }^{13}$ assessment was used to analyse child's motor capability and allowed to draw the motor development curve (MDC) ${ }^{14}$ for each SG child. All GMFM evaluations in this study were performed by the same trained author of this study, MBZ.

\section{Outcomes measures used in comparing the groups}

For the cross-sectional study, the data from the final assessment of the SG were considered, after three years of follow-up, compared to the data of the first assessment of the CG, before any kind of intervention in this group. The final evaluation of SG was held in conjunction with the sixth assessment of motor function, not considering a specific period after BTX-A session.

Gender, presence of epilepsy, number of adverse events in the prenatal and perinatal periods, classification according to GMFCS and data from the evaluation of the range of 
active extension of the wrist were considered, besides the speed of hand movements (Figs 1 and 2), PRS score ${ }^{12}$, spasticity $^{10}$, muscular strength, sensitivity function and the presence of hemineglect, as assessed by the WISC IV subtest ${ }^{15}$. Neuroimage classification ${ }^{16}$ and intelligence quotient (IQ) ${ }^{15}$ were also considered by the authors of this study, ACN and SM, respectively.

The GMFM ${ }^{13}$ score allowed comparing the best positioning in relation to the median in the motor development curves (MDC) for $\mathrm{CP}$ for $\mathrm{CP}^{14}$. The Pediatric Evaluation of Disability Inventory (PEDI) ${ }^{17}$ was used to assess the child's actual performance during day-to-day life and the positioning in relation to the third percentile for the Pediatric Physical Functioning Reference Curves (PPFRC) for self-care and mobility ${ }^{18}$. All PEDI ${ }^{17}$ evaluations were performed by the same trained author of this study, MP. The assessment tools GMFM ${ }^{13}$, GMFCS 9 , $\mathrm{PEDI}^{17}$ and $\mathrm{PRS}^{12}$ are considered valid and reliable for assessing functional ability of children with cerebral palsy ${ }^{19}$.

\section{Statistics}

For the association between quantitative variables, the Spearman correlation coefficient was estimated. In order to compare the quantitative variables between the two independent subgroups, either Student's $t$-test or Mann-Whitney non-parametric test was considered appropriate. Fisher's exact test was used for comparisons between dichotomous nominal variables and Student's $t$-test was used for dependent variables; $p<0.05$ was considered statistically significant. Statistica/w v.5.1 ${ }^{\circledR}$ software was applied for the analyses.

\section{RESULTS}

Twenty-four children participated in the study, and detailed data for each child are provided in Table 1.

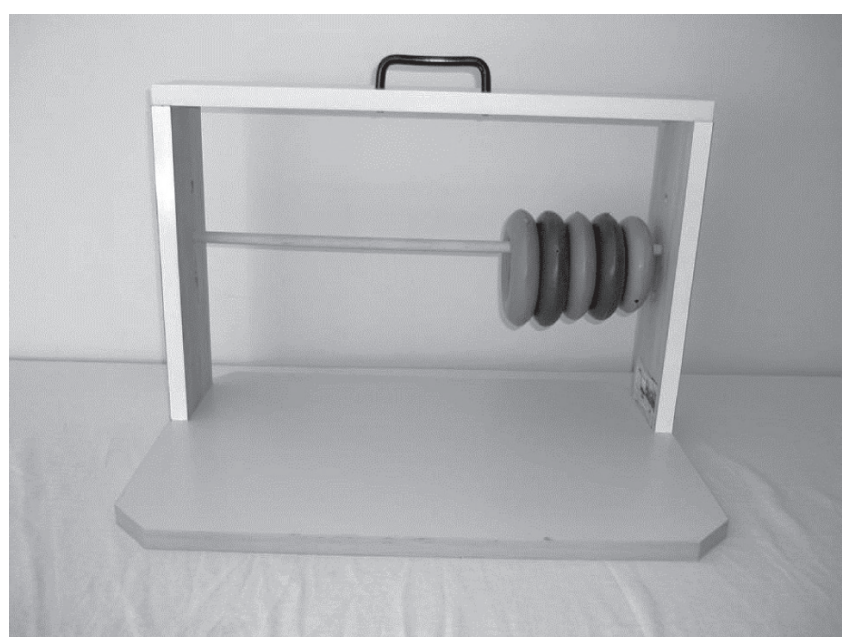

Fig 1. Standardised support for transferring the rings.

\section{Data on spasticity treatment of the study group}

The SG was composed of 11 HCP children and included 8 boys and 8 (73\%) children with left-side involvement. Treatment of spasticity started at a mean age of 9 months $( \pm 3)$ and ranged from 6 to 15 months. The mean follow-up time was 36.63 months $( \pm 6.31)$. The total number of BXT-A sessions was 41 . One patient accomplished only one session, two accomplished three sessions, six accomplished four sessions and two were subjected to five sessions, and adverse effects were not reported. There was an intervention targeting the upper limbs in all sessions and targeting the lower limbs in 34 ones (83\%). To compare muscle tone in each child, 11 muscles were evaluated at the beginning and at the end of the study period. In 64 (53\%) evaluations, the tonus remained stable, there was a decrease in 40 (33\%) cases, and an increase in 17 (14\%) ones. Data on the BXT-A treatment for the SG, the frequency of the muscles injections and data on changes in muscle tone from the begining to the end of the study are available in Table 2 . The range of passive wrist extention remained at good levels for the duration of the study and the range of active wrist extention increased in six patients (Table 3 ). The only patient who showed decreased in the active range of wrist extention was patient 3, level II in the GMFCS, and the only in both groups with Large-vessel arterial infarct in the left internal carotid artery.

The first evaluation using the GMFM was conducted when the BXT-A was first indicated, and there were a total of six evaluations during the study. The total score obtained in each GMFM was compared to the functional level as assessed by the GMFCS and with the MDC for HCP. Improvement in the MDC was observed in seven patients, while three were maintained at good levels and one (patient 3) was below average (-2SD) (Table 4). No adverse reactions were observed or any negative effects of the BTX-A sessions in the functional capacity of any child of the SG.

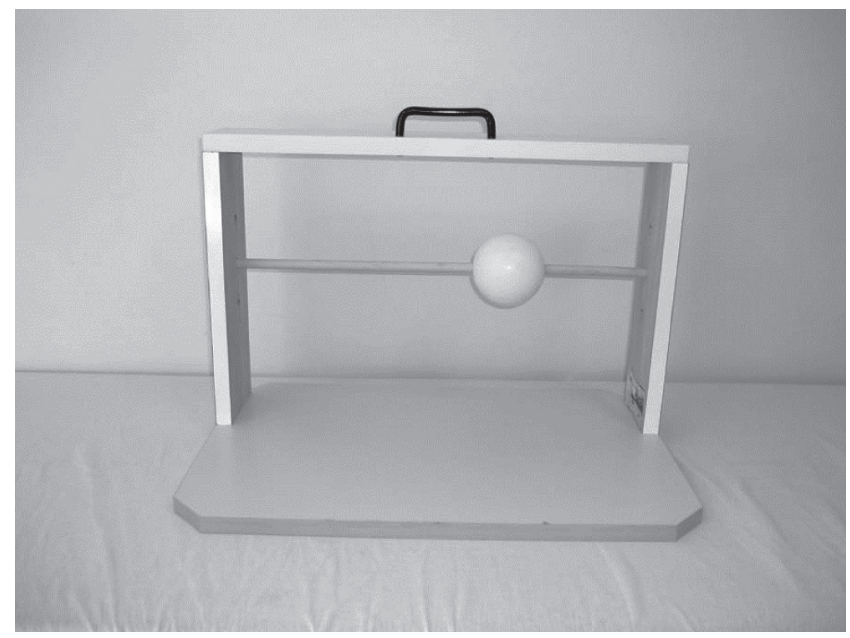

Fig 2. Standardised support for transferring the ball. 
Table 1. Individual characteristics of children in the study and the comparison groups.

\begin{tabular}{|c|c|c|c|c|c|c|c|c|c|c|c|c|c|c|c|}
\hline & $a$ & ৫ & $\underset{\mathbb{\infty}}{\stackrel{\infty}{\leftarrow}}$ & $\begin{array}{l}\frac{0}{0} \\
\frac{0}{0} \\
\stackrel{0}{0} \\
\underline{a}\end{array}$ & 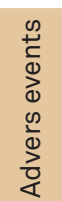 & $\begin{array}{l}\frac{\pi}{\infty} \\
\frac{0}{0} \\
\frac{0}{0} \\
\frac{1}{山}\end{array}$ & 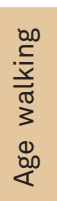 & 离 & 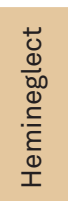 & $\begin{array}{l}\infty \\
\text { 心 } \\
\sum_{0}^{\amalg}\end{array}$ & 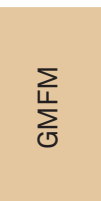 & $\begin{array}{l}0 \\
\stackrel{0}{3} \\
0 \\
\vdots \\
\vdots \\
\vdots \\
\vdots\end{array}$ & 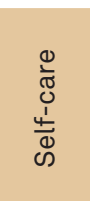 & 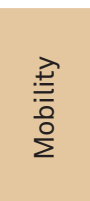 & 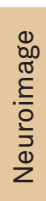 \\
\hline \multirow{11}{*}{ 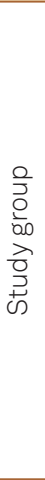 } & 1 & $M$ & 41 & $L$ & No & Yes & 24 & 30 & No & 1 & $81 \%$ & $5 \% \downarrow$ Med & $23 \% \downarrow$ & $16 \% \downarrow$ & 1 \\
\hline & 2 & $M$ & 41 & L & Yes & Yes & 24 & 20 & No & I & $94.1 \%$ & Med & $5 \% \downarrow$ & $15 \% \downarrow$ & 1 \\
\hline & 3 & $M$ & 41 & $R$ & Yes & No & 32 & -30 & Yes & $\|$ & $58.5 \%$ & $10 \% \downarrow-$ & $16 \% \downarrow$ & $9 \% \downarrow$ & 4 \\
\hline & 4 & $M$ & 55 & $\mathrm{R}$ & Yes & No & 23 & 0 & No & I & $98.3 \%$ & $2 \% \uparrow+2 S D$ & $6 \% \downarrow$ & $7 \% \downarrow$ & 2 \\
\hline & 5 & $\mathrm{~F}$ & 48 & $\mathrm{R}$ & Yes & No & 13 & 30 & Yes & 1 & $93.8 \%$ & Med & $11 \% \downarrow$ & $7 \% \downarrow$ & 2 \\
\hline & 6 & M & 53 & $\mathrm{~L}$ & Yes & No & 18 & 10 & Yes & I & $97 \%$ & $1 \% \uparrow+2$ SD & $17 \% \downarrow$ & $5 \% \downarrow$ & 3 \\
\hline & 7 & M & 45 & $\mathrm{~L}$ & Yes & No & 19 & 45 & No & । & $94.7 \%$ & $5 \% \uparrow M e d$ & $1 \% \uparrow$ & $5 \% \downarrow$ & 2 \\
\hline & 8 & M & 55 & $\mathrm{~L}$ & No & No & 17 & 90 & No & 1 & $93.2 \%$ & $5 \% \uparrow M e d$ & $6 \% \downarrow$ & $13 \% \downarrow$ & 5 \\
\hline & 9 & M & 46 & L & Yes & No & 18 & 90 & No & 1 & $95 \%$ & $2 \% \uparrow+2 S D$ & $3 \% \uparrow$ & $5 \% \downarrow$ & 3 \\
\hline & 10 & $\mathrm{~F}$ & 38 & L & Yes & No & 18 & 30 & Yes & I & $92 \%$ & $5 \% \uparrow M e d$ & $9 \% \downarrow$ & $3 \% \downarrow$ & 2 \\
\hline & 11 & $\mathrm{~F}$ & 39 & $\mathrm{~L}$ & Yes & Yes & 20 & 60 & No & I & $93 \%$ & $5 \% \uparrow \mathrm{Med}$ & $23 \% \downarrow$ & $6 \% \downarrow$ & 1 \\
\hline \multirow{13}{*}{ 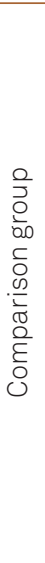 } & 1 & $M$ & 40 & $L$ & Yes & No & 20 & 10 & No & 1 & $92.5 \%$ & 5\%^Med & $11 \% \downarrow$ & $1 \% \uparrow$ & 3 \\
\hline & 2 & $M$ & 39 & $\mathrm{~L}$ & No & No & 15 & 10 & No & II & $92 \%$ & $1 \% \uparrow+2$ SD & $13 \% \downarrow$ & $1 \% \downarrow$ & 2 \\
\hline & 3 & M & 51 & $L$ & No & No & 48 & 10 & \# & 1 & $53 \%$ & $17 \% \downarrow-2$ SD & $13 \% \downarrow$ & $37 \% \downarrow$ & 4 \\
\hline & 4 & M & 41 & $R$ & No & No & 24 & 10 & No & 1 & $90.3 \%$ & 1\%^Med & $36 \% \downarrow$ & $23 \% \downarrow$ & 2 \\
\hline & 5 & $\mathrm{~F}$ & 39 & $\mathrm{R}$ & No & No & 20 & 45 & No & 1 & $93 \%$ & $5 \% \uparrow M e d$ & $26 \% \downarrow$ & $11 \% \downarrow$ & 1 \\
\hline & 6 & M & 45 & $\mathrm{R}$ & Yes & No & 12 & -30 & Yes & । & $86 \%$ & Med & $12 \% \downarrow$ & $10 \% \downarrow$ & 2 \\
\hline & 7 & $M$ & 53 & $\mathrm{R}$ & Yes & No & 30 & 90 & No & I & $96 \%$ & $1 \% \uparrow M e d$ & $10 \% \downarrow$ & $14 \% \downarrow$ & 2 \\
\hline & 8 & M & 46 & $\mathrm{R}$ & Yes & No & 30 & -60 & Yes & । & $72 \%$ & $8 \% \downarrow-2$ SD & $18 \% \downarrow$ & $2 \% \downarrow$ & 3 \\
\hline & 9 & M & 41 & $\mathrm{R}$ & Yes & No & 16 & 20 & No & I & $85.6 \%$ & $3 \% \downarrow \mathrm{Med}$ & $10 \% \downarrow$ & $8 \% \downarrow$ & 1 \\
\hline & 10 & M & 58 & $\mathrm{R}$ & No & No & 14 & 70 & Yes & 1 & $95.6 \%$ & Med & $10 \% \downarrow$ & $6 \% \downarrow$ & 1 \\
\hline & 11 & $\mathrm{~F}$ & 50 & $\mathrm{~L}$ & Yes & No & 36 & 10 & \# & 1 & $80.2 \%$ & $1 \% \downarrow-2 S D$ & $5 \% \downarrow$ & $20 \% \downarrow$ & 4 \\
\hline & 12 & M & 41 & $\mathrm{R}$ & No & No & 12 & 30 & Yes & I & $95 \%$ & 7\%^Med & $33 \% \downarrow$ & $12 \% \downarrow$ & 1 \\
\hline & 13 & M & 53 & $\mathrm{~L}$ & Yes & No & 13 & 0 & No & 1 & $96 \%$ & Med & $3 \% \downarrow$ & $9 \% \downarrow$ & 2 \\
\hline
\end{tabular}

P: patient; G: gender; M: masculine; F: feminine; Age: age (months) of evaluation; Invol Side: side of involvement; L: left; R: right; Adverse events: presence of adverse events at birth; Epilepsia: presence of epilepsia; Age Walking: age (months) of acquisition of independent walking; Wrist Extention: range of active extention of the wrist; GMFCS: Gross Motor Function Classification System; GMFM: total score in the Gross Motor Function Measure; MDC: distance to the median in the Motor Development Curve; Self-Care - distance to the $3^{\text {th }}$ percentile in the Pediatric Physical Functioning Reference Curve (PPFRC) for self-care; Mobility - distance to the 3th percentile in the PPFRC for mobility; Neuroimage - neuroimage classification: 1. Maldevelopment, 2. Periventricular Atrophy, 3. Cortical/Subcortical Atrophy, 4. Miscelaneous, 5. Normal; Med: median; \#: data not obtained; $\uparrow$ above; $\downarrow$ below.

\section{Data regarding the comparison between groups}

Twenty-four children with HCP - mean age of $49.3 \pm 5.2$ months and an age range of 39 to 60 months participated in the study. CG was composed of 13 HCP children and included 11 boys and $5(38 \%)$ children with left-side involvement.

There was no significant difference between groups regarding the number of adverse events in pre- and perinatal periods $(\mathrm{p}=0.21)$, presence of epilepsy $(\mathrm{p}=0.08)$, gender $(p=0.63)$ or classification according to the GMFCS $(p=1)$. Due to the sample size and the presence of a variety of neuroimaging classifications, it was not possible to compare the data between the groups.

Children from both groups were referred to physiotherapy. At the time of the cross-sectional assessment, 18 patients had follow-up with physical therapy for over 2 years $(75 \%)$ and 6 (25\%) for less than 2 years. This variable could not be controlled due to the different children's backgrounds and the variety of types, frequency and intensity of the physiotherapy treatment that they received.

There was no statistically significant difference between the groups regarding sensitivity function, spasticity, muscle strength and the presence of hemineglect ${ }^{19}$.

The SG subjects exhibited a higher active extension of the wrist, a higher percentage of balls and rings transferred and a higher PRS score than the CG subjects; however, there was no significant difference (Table 5). The GMFM scores of the SG subjects were higher in four of the five dimensions and were significantly higher for dimension B. The SG subjects presented with higher than average scores and less variation compared to the $\mathrm{CG}$ in terms of variation relative to the median in the MDC; nevertheless, there was no significant difference $(p=0.53)$. The SG showed higher scores in five of the six areas evaluated in the PEDI (Table 5) and were closer to the third percentile for both self-care and mobility in the PPFRC, but this difference was not significant. 
Table 2. Average dose of botulinum neurotoxin type A used in each year of life in the study group children, number of sessions and frequency of the muscle injections per session, besides the changes in muscle tonus considering the initial and the final tonus evaluation.

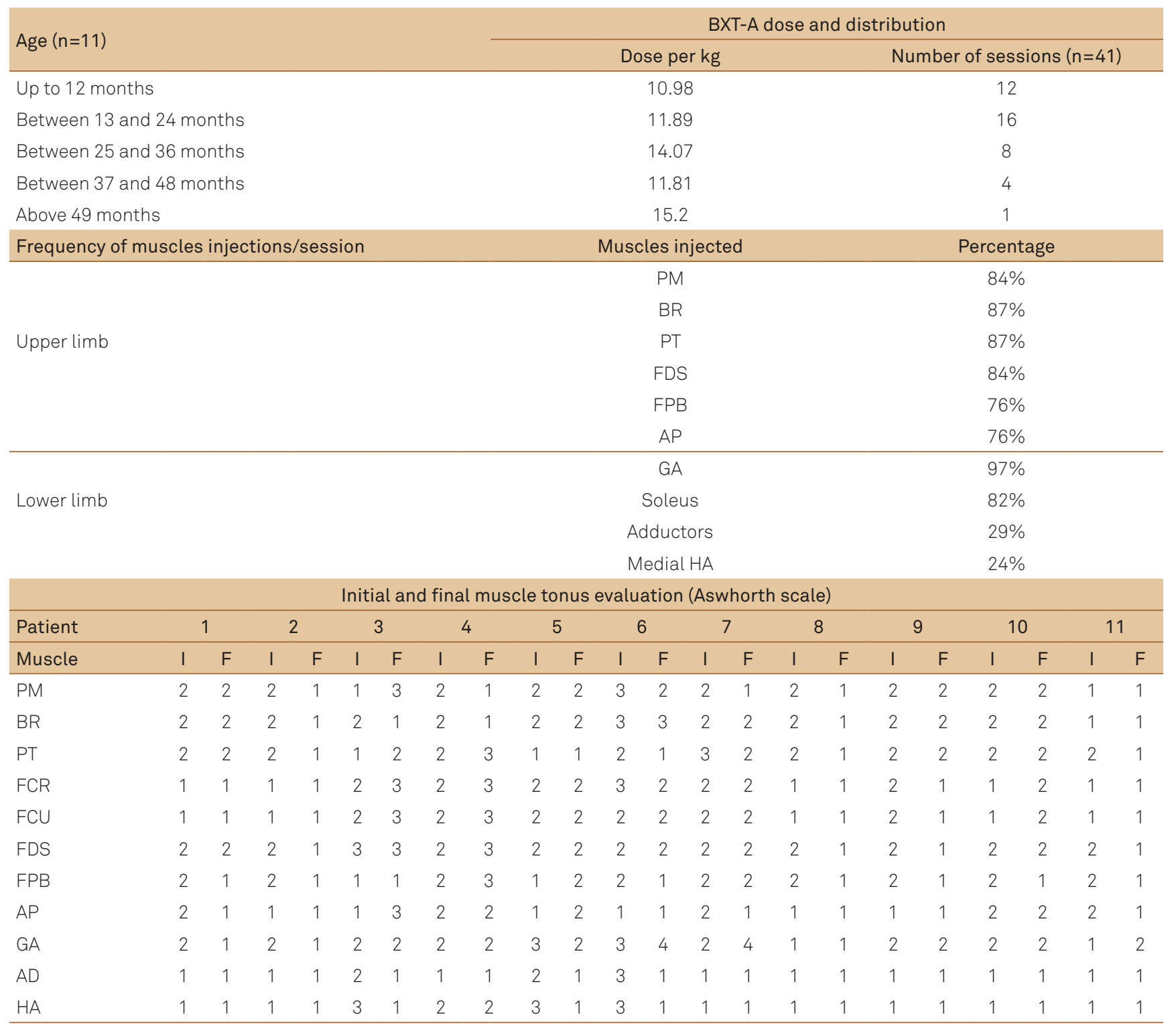

I: initial; F: final; PM: pectoralis major; BR: braquioradialis; PT: pronador teres; FCR: flexor carpi radialis; FCU: flexor carpi ulnaris; FDS: flexor digitorum superficialis; FPB: flexor pollicis brevis;AP: adductor pollicis; GA: gastrocnemius; AD: adductors; HA: hamstrings; BXT-A: botulinum neurotoxin type A.

\section{DISCUSSION}

This study was designed to address when BTX-A treatment should be started for CP children with spasticity. In addition to the results relating to the early spasticity treatment offered to a group of CP patients, we also compared the functional results of this group with one that did not receive this treatment. The results allow us to partially answer the question which led to the study when considering the improvement in the motor trajectory of the SG and also the better functional outcomes for this group, compared to the CG.
$\mathrm{CP}$ is characterised by a limitation to perform activities that begins with impaired motor development, which is especially exacerbated by a relative deprivation of experience with regard to mobility and learning ${ }^{20}$. Various combinations of sensory impairment, spasticity and/or reduced muscle length associated with spasticity contribute to the patient's difficulties in reaching, pointing, grasping, releasing and manipulating objects ${ }^{21}$. In the lower limbs, spasticity contributes to the difficulty in transferring weight onto the involved side, in the acquisition of standing balance and in independent walking $^{22}$. Rehabilitation therapies are usually started as soon 
Table 3. Range of movement at initial and final evaluations of the study group children.

\begin{tabular}{lcccc} 
& \multicolumn{2}{c}{ Passive extension of the wrist } & \multicolumn{2}{c}{ Active extension of the wrist } \\
\cline { 2 - 4 } Patient & Initial & Final & Initial & 30 \\
1 & 90 & 90 & 30 & 20 \\
2 & 90 & 90 & $*$ & -30 \\
3 & 90 & 90 & 0 & 0 \\
4 & 70 & 75 & $*$ & 30 \\
5 & 90 & 90 & 20 & 10 \\
6 & 90 & 90 & 20 & 45 \\
7 & 60 & 90 & 30 & 90 \\
9 & 90 & 90 & 10 & 90 \\
10 & 90 & 90 & 90 & 30 \\
\hline
\end{tabular}

*No obtained data by younger age and/or no cooperation of the patient.

Table 4. Gross Motor Function Classification System and positioning in the motor development curves for cerebral palsy in each Gross Motor Function Measure evaluation of the study group children.

\begin{tabular}{|c|c|c|c|c|c|c|c|}
\hline Patient & GMFCS & GMFM 1 & GMFM 2 & GMFM 3 & GMFM 4 & GMFM 5 & GMFM 6 \\
\hline 1 & 1 & & $17 \% \downarrow-2 S D$ & 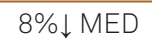 & $20 \% \downarrow-2 S D$ & $20 \% \downarrow$ MED & $5 \% \downarrow M E D$ \\
\hline 2 & । & & & 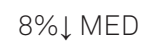 & $2 \% \downarrow-2$ SD & 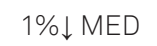 & MED \\
\hline 3 & $\|$ & $2 \% \downarrow-2 \mathrm{SD}$ & $2 \% \downarrow M E D$ & $3 \% \downarrow-2$ SD & $5 \% \downarrow-2$ SD & $20 \% \downarrow M E D$ & $10 \% \downarrow-2$ SD \\
\hline 4 & । & & $2 \% \uparrow M E D$ & $2 \% \uparrow M E D$ & $2 \% \uparrow M E D$ & $2 \% \uparrow+2 S D$ & $2 \% \uparrow+2 \mathrm{SD}$ \\
\hline 5 & । & & $8 \% \downarrow M E D$ & $3 \% \uparrow M E D$ & MED & MED & MED \\
\hline 6 & । & $5 \% \uparrow+2 S D$ & $5 \% \uparrow+2 \mathrm{SD}$ & $2 \% \uparrow+2 S D$ & $5 \% \uparrow M E D$ & $5 \% \uparrow M E D$ & $1 \% \uparrow+2 \mathrm{SD}$ \\
\hline 7 & । & & $12 \% \downarrow-2 S D$ & 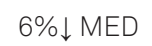 & $6 \% \downarrow$ MED & MED & $5 \% \uparrow M E D$ \\
\hline 8 & । & & & $8 \% \uparrow M E D$ & $2 \% \uparrow M E D$ & 1\%个MED & $5 \% \uparrow M E D$ \\
\hline 9 & । & & $20 \% \uparrow+2$ SD & $8 \% \uparrow+2 \mathrm{SD}$ & $8 \% \uparrow M E D$ & $2 \% \uparrow+2$ SD & $2 \% \uparrow+2 \mathrm{SD}$ \\
\hline 10 & । & & & $1 \% \downarrow$ MED & $5 \% \uparrow M E D$ & MED & $5 \% \uparrow \mathrm{MED}$ \\
\hline 11 & । & & $2 \% \downarrow-2$ SD & $2 \% \uparrow+2 S D$ & $1 \% \uparrow+2 \mathrm{SD}$ & $4 \% \uparrow M E D$ & $5 \% \uparrow M E D$ \\
\hline
\end{tabular}

GMFCS: Gross Motor Function Classification System; GMFM (1 to 6): position in the curve from the first to the sixth Gross Motor Function Measure; SD: standard deviation; MED: median; $\uparrow$ above; $\downarrow$ below.

as motor deficits are observed and are aimed to influence motor learning ${ }^{23}$.

Even though authors, such as Pascual-Pascual and Pascual-Castroviejo ${ }^{24}$ and Delgado et al..$^{25}$, have demonstrated a good safety profile for BTX-A in infants younger than 2 years and an increase in their responsiveness to physiotherapy treatment, BTX-A is usually initiated around 2 years old $^{7,26}$. We had previously demonstrated that younger patients exhibit a greater reduction in spasticity after intervention than older patients ${ }^{6}$. The expected benefit of the intervention is to provide a more appropriate sensorimotor experience at a critical period of neurodevelopment, which may influence subsequent motor learning and improve function ${ }^{27}$.

In this study, spasticity in children of the SG was treated as soon as it affected the child's function. The treatment protocol was guided by observing the target functional status for each individual child. Although all children have the same diagnosis of HCP, there was great variation in dose, location, age, number and range of applications, which reflects the clinical variability, pointing to the need for individualized assessments, very comprehensive and focused on the functional development.
Both the muscle tone and range of motion in the SG remained at good levels, with no structure deformities occurring during evolution. The fact that the final evaluation of this group has not been done in post BTX-A session may be one factor that explains the increased muscle tone in some cases. But from a functional standpoint, the patients had a good outcome. Three infants who had a reduced ability to extend their wrists during the first assessment showed improvement in this measure during treatment and final assessment. Among those that were measured in the beginning, most improved their active range of motion. Beckung et al. ${ }^{14}$ published the MDC for CP patients, which have been developed to assist in planning treatment and evaluating outcomes after intervention. These curves do not represent the natural course of motor development in CP but consider the trajectory over time for children undergoing treatments considered appropriate in light of current knowledge in developed countries, according to different topographical distributions. From this point of view, the observation, in this study, that seven patients improved their positions in their MDC is even more important and may be associated with the early treatment of spasticity. 
Table 5. Comparison between groups concerning developmental and functional data.

\begin{tabular}{|c|c|c|c|c|c|c|c|}
\hline \multirow{2}{*}{ Variables } & \multicolumn{3}{|c|}{ Study group } & \multicolumn{3}{|c|}{ Comparison group } & \multirow{2}{*}{$p$-value } \\
\hline & Mean & SD & Range & Mean & SD & Range & \\
\hline \multicolumn{8}{|l|}{ Age (months) } \\
\hline At evaluation & 45.64 & 6.3 & $38-55$ & 45.92 & 6.4 & $39-58$ & 0.914 \\
\hline Signs of hemiplegia & 4.36 & 1.43 & $2-6$ & 6.5 & 4.8 & $1-16$ & 0.566 \\
\hline Head control & 5.36 & 1.86 & $3-9$ & 5.5 & 3.23 & $3-12$ & 0.566 \\
\hline Sitting control & 9.18 & 2.4 & $6-12$ & 10.36 & 5.32 & $6-24$ & 0.949 \\
\hline Independent walking & 20.55 & 5.03 & $13-32$ & 22.31 & 10.96 & $12-48$ & 0.820 \\
\hline \multicolumn{8}{|l|}{ Cognitive function } \\
\hline Performance & 71.09 & 19.10 & $47-106$ & 77 & 26.29 & $47-126$ & 0.833 \\
\hline Verbal & 82.55 & 15.80 & $52-105$ & 88.92 & 30.16 & $48-152$ & 0.740 \\
\hline Total & 74.55 & 18.27 & $45-101$ & 81.83 & 30.94 & $43-141$ & 0.833 \\
\hline \multicolumn{8}{|l|}{ GMFM (\%) } \\
\hline Dimension A & 96 & 10 & $68.6-100$ & 98 & 3 & $90-100$ & 0.820 \\
\hline Dimension B & 97 & 7 & $76.6-100$ & 94 & 6 & $83.3-100$ & 0.035 \\
\hline Dimension C & 89 & 26 & $14.2-100$ & 83 & 28 & $16.6-100$ & 0.361 \\
\hline Dimension D & 89 & 5 & $82-97.4$ & 84 & 16 & $33.3-100$ & 0.459 \\
\hline Dimension E & 82 & 13 & 49-94 & 74 & 15 & $36.1-90.2$ & 0.134 \\
\hline Total score & 91 & 12 & $58.5-98.3$ & 87 & 12 & $53-96$ & 0.119 \\
\hline \multicolumn{8}{|l|}{ PEDI } \\
\hline \multicolumn{8}{|l|}{ FS normative score } \\
\hline Self-care & 35.04 & 9,07 & $18-50$ & 23.71 & 20,3 & $-10-41.4$ & 0.277 \\
\hline Mobility & 27.40 & 7.95 & $12.2-35.9$ & 22.02 & 25,12 & $-10-56$ & 0.608 \\
\hline Social function & 27.13 & 15.88 & $-10-46.8$ & 32.64 & 12.23 & $13.7-52$ & 0.424 \\
\hline \multicolumn{8}{|l|}{ CA normative score } \\
\hline Self-care & 43.92 & 14.24 & $23.3-68.6$ & 31.25 & 21.32 & $-10-52$ & 0,424 \\
\hline Mobility & 39,95 & 13.70 & $12.7-58.8$ & 33.28 & 19.17 & $-10-58.3$ & 0,494 \\
\hline Social function & 52.47 & 13.62 & $27.5-68.7$ & 49.70 & 12.31 & $24-68.9$ & 0,569 \\
\hline Distance MDC (cm) & 0.64 & 6.31 & $-16-5$ & -2.15 & 8.91 & $-20-7$ & 0.531 \\
\hline \multicolumn{8}{|l|}{ Distance in PPFRC } \\
\hline Self-care & 9.09 & 7.71 & $-3-23$ & 14.85 & 10.61 & $3-36$ & 0.252 \\
\hline Mobility & 8.27 & 4.43 & $3-36$ & 11.69 & 10.28 & $-1-37$ & 0.459 \\
\hline \multicolumn{8}{|l|}{ Range of moviment } \\
\hline Active wrist extension & 34,09 & 36.25 & $-30-90$ & 16,54 & 38.48 & $-60-90$ & 0.228 \\
\hline \multicolumn{8}{|l|}{ Hand moviment velocity } \\
\hline Transfer of the ball (\%) & 49.53 & 23.14 & $22-100$ & 43.20 & 23.49 & $10-95$ & 0.566 \\
\hline Transfer of the rings (\%) & 50.49 & 24.16 & $22-100$ & 50.04 & 12.45 & $35-77$ & 0.740 \\
\hline Physician's Rating Scale & 13 & 2 & $10-14$ & 11.61 & 2.4 & $7-14$ & 0.424 \\
\hline
\end{tabular}

SD: standard deviation; GMFM: Gross Motor Function Measure; PEDI: Pediatric Evaluation Disability Inventory; FS: functional skills; CA: caregiver assistance; MDC: Motor Development Curve; PPFRC: Pediatric Physical Functioning Reference Curves.

Comparing both groups, children from the SG showed higher active extension of the wrist, movement velocity and PRS scores than the CG. They also showed better position in the MDC and higher scores in the GMFM ${ }^{13}$, especially in dimension b. One way to measure the impact of $\mathrm{CP}$ is to measure a patient's difficulties in performing daily activities ${ }^{27}$. Information pertaining to the difficulty in carrying out these activities is highly relevant because this is usually the main complaint of affected children, parents and relatives $^{28}$. Children of the SG showed higher scores in the PEDI ${ }^{17}$ and a better position in the PPFRC ${ }^{18}$, which, in everyday life, means greater independence in activities related to self-care and mobility and less of a need for caregiver assistance. It should be noted that although the results do not show significance, the SG had better functional outcomes than the
CG, especially in the GMFM scores ${ }^{13}$, which is considered the gold standard for the development of motor skills.

The acquisition of developmental milestones was similar in both groups. However, independent walking occurred earlier in the SG, and a lower percentage of these children started walking after 2 years of age. Bleck ${ }^{29}$ stated that most children with HCP begin to walk independently between 18 and 21 months of age and that the limiting factors for this acquisition are mental retardation, behaviour disorders and epilepsy. The study by Beckung et al..$^{30}$ showed that, in children with $\mathrm{CP}$, the variable that was most often associated with the prognosis of walking was intellectual capacity; however, this report was unable to show that intellectual impairment was responsible for the inability to walk. These findings suggest the importance of cognitive ability in the acquisition 
of functional skills that require auto-perception and adaptation to the environment. Children from the SG had lower IQ scores into both verbal and performance areas than those of the CG. Nevertheless, they presented with better functional results, which could have been related to the treatment. These outcomes were associated with an absence of adverse reactions, thereby indicating the benefit of early treatment with BXT-A.

The study limitations were: no randomisation, HCP clinical heterogeneity, sample size, physiotherapy not controlled and associated comorbidities. Ideally, the CG should have been selected randomly from patients at the same clinic. However, this possibility was abandoned for ethical reasons and because of the unanimous parent concordance for BXT-A use. The randomization of the groups probably would not help to form more homogeneous groups. The heterogeneity of the injury makes it a challenge to compare children with CP. The motor difficulty observed varied considerably within the same topographic and functional classification, confirming the reports in the literature that there are not two children with CP affected in the same way ${ }^{20}$.

The ideal would be controlled physiotherapy, with a targeted approach to the task, so ecological and intensive ${ }^{23}$. But in studies like the present one, with evaluation measures for long periods of time in patients coming from different backgrounds, it is impossible to control all the variables that may contribute to functional improvement. Nor only physiotherapy but different therapies may have contributed in the development of motor and cognitive skills in both groups, including environmental enrichment. Different uncontrolled factors such as life situations, child personality and familial styles can also influence the developmental trajectory and are not amenable to change.

The decision to treat spasticity in children with HCP, especially infants, is complicated due to the existence of several factors that may influence treatment outcome, including patient's phase of accelerated growth and level of psychomotor development. Although spasticity is highlighted as the main cause of disability ${ }^{4}$, hemineglect, sensibility and strength impairment also affect the outcome of motor rehabilitation. However, the long-term followup of a group who received early spasticity treatment with BXT-A, together with guidelines from a multidisciplinary team, shows that it is possible to change the motor trajectory of these individuals. The reduction of muscle tone in itself is not the most important outcome in this study, but rather the change in trajectory of the functional study subjects. The comparing of this SG with another group of children who did not have access to this management shows that the SG had better functional outcomes. The results of this study, especially the positive development of children in the SG, suggest that further researches with larger populations are needed to determine the optimal timing of early spasticity therapy.

\section{References}

1. Autti-Rämö I, Larsen A, von Wendt L, Taimo A. Management of the upper limb with botulinum toxin type A in children with spastic type cerebral palsy and acquired brain injury: clinical implications. Eur $J$ Neurol 2001;8:136-144.

2. Msall ME, Park JJ. Neurodevelopmental management strategies for children with cerebral palsy: optimizing function, promoting participation, and supporting families. Clin Obstet Gynecol 2008;51:800-815.

3. World Health Organization (WHO). International Classification of Functioning, Disability and Health. Geneva:WHO; 2001.

4. Bjornson K, Hays R, Graubert C, et al. Botulinum toxin for spasticity in children with cerebral palsy: a comprehensive evaluation. Pediatrics 2007;120:49-58.

5. Lukban MB, Rosales RL, Dressler D. Effectiveness of botulinum toxin A for upper and lower limb spasticity in children with cerebral palsy: a summary of evidence. J Neural Transm 2009;116:319-331.

6. Coutinho dos Santos LH, Bufara Rodrigues DC, Simões de Assis TR, Bruck I. Effective results with botulinum toxin in cerebral palsy. Pediatr Neurol 2011;44:357-363.

7. Love SC, Valentine JP, Blair EM, et al. The effect of botulinum toxin type A on the functional ability of the child with spastic hemiplegia: a randomized controlled trial. Eur J Neurol 2001:8:S50-S58.

8. Graham HK, Aoki KR, Autti-Rämö I, et al. Recommendations for the use of botulinum toxin type $\mathrm{A}$ in the management of cerebral palsy. Gait Posture 2000;11:67-79.

9. Palisano R, Rosenbaum P, Walter S, et al. Development and reliability of a system to classify gross motor function in children with cerebral palsy. Dev Med Child Neurol 1997;39:214-223.
10. Edgar TS. Clinical utility of botulinum toxin in the treatment of cerebral palsy: comprehensive review.J Child Neurol 2001;16:37-46.

11. Ashworth B. Preliminary trial of carisoprodol in multiple sclerosis. Practitioner 1964;192:540-542.

12. Koman LA, Brashear A, Rosenfeld S, et al. Botulinum toxin type A neuromuscular blockade in the treatment of equinus foot deformity in cerebral palsy: a multicenter, open-label clinical trial. Pediatrics 2001;108:1062-1071.

13. Russell DJ, Rosenbaum PL, Cadman DT, et al. The gross motor function measure: a mean to evaluate the effects of physical therapy. Dev Med Child Neurol 1989;31:341-352.

14. Beckung E, Carlsson G, Carlsdotter S, Uvebrant P. The natural history of gross motor development in children with cerebral palsy aged 1 to 15 years. Dev Med Child Neurol 2007;49:751-766.

15. Wechsler D. Wechsler Preschool and Primary Scale of Intelligence Revised David Wechsler. The Psychological Corporation Harrourt Brace Jovanovich, 1989.

16. Wicklund LM, Uvebrant P, Flodmark O. Morphology of cerebral lesions in children with congenital hemiplegia. A study with computed tomography. Neuroradiology 1990;32:179-186.

17. Haley SM, Coster WJ, Ludlow LH, et al. Pediatric evaluation of disability inventory: development, standardization and administration manual. Boston: New England Medical Center; 1991.

18. Haley SM, Fragala-Pinkham MS, Sheng PS, et al. Pediatric physical functioning reference curves. Pediatr Neurol 2004;31:333-341.

19. Zonta MB. Efeitos do tratamento da espasticidade com toxina botulínica do tipo A na função motora grossa de lactentes com 
Paralisia Cerebral forma Hemiplégica [Thesis]. Curitiba: Universidade Federal do Paraná; 2009.

20. Rosenbaum P. Cerebral palsy: what parents and doctors want to know. BMJ 2003;326:970-974.

21. Boyd RN, Morris ME, Grahan HK. Management of upper limb dysfunction in children with cerebral palsy: a systematic review. Eur J Neurol 2001;8:S150-S166.

22. Zonta MB, Ramalho Junior A, Camargo RMR, et al. Two-dimensional analysis of gait asymmetry in spastic hemiplegia. Einstein 2010;8:343-349.

23. Ahl LE, Johansson E, Carlberg EB. Functional therapy for children with cerebral palsy: an ecological approach. Dev Med Child Neurol 2005;47:613-619.

24. Pascual-Pascual SI, Pascual-Castroviejo I. Safety of botulinum toxin type A in children younger than 2 years. Eur J Neurol 2009;13:511-515.

25. Delgado MR, Wilson $\mathrm{H}$, Johnston $\mathrm{C}$, et al. A Preliminary report of the use of botulinum toxin type $A$ in infants with clubfoot: four case studies. J Pediatr Orthop 2000;20:533-538.
26. Molenaers G, Schörkhuber V, Fagard K, et al. Long-term use of botulinum toxin type $A$ in children with cerebral palsy: treatment consistency. Eur J Paediatr Neurol 2009;13:421-429.

27. Nordmark E, Jarnlo GB, Hägglund G. Comparison of the Gross Motor Function Measure and Paediatric Evaluation of Disability Inventory in assessing motor function in children undergoing selective dorsal rhizotomy. Dev Med Child Neurol 2000;42:245-252.

28. Mancini MC, Fiúza PM, Rebelo JM, et al. Comparação do desempenho de atividades funcionais em crianças com desenvolvimento normal e crianças com paralisia cerebral. Arq Neuropsiquiatr 2002;60:446-452.

29. Bleck EE. Locomotor prognosis in cerebral palsy. Dev Med Child Neurol 1975;17:18-25.

30. Beckung E, Hagberg G, Uldall P, Cans C; Surveillance of Cerebral Palsy in Europe. Probability of walking in children with cerebral palsy in Europe. Pediatrics 2008;121:e187-e192. 